\section{NEGRAS INTELECTUAIS E ENSINO DE PSICOLOGIA: EPISTEMICÍDIO E REPRESENTATIVIDADE}

\section{BLACK INTELLECTUAL WOMEN AND PSYCHOLOGY TEACHING: EPISTEMICIDE AND REPRESENTATIVITY}

Gerluce de Jesus Santos ${ }^{1} /$ Joseane Vilarino da Cruz Santos ${ }^{1} /$ Pablo Mateus dos Santos Jacinto ${ }^{1, *} /$ Adelmo dos Santos Filho ${ }^{2}$

\section{INTRODUÇÃO}

Discutir a representatividade de negras intelectuais no ensino curricular dos cursos de psicologia é um dos principais pontos que orientam este estudo. $\mathrm{O}$ trabalho se expressa pela inquietação de negras universitárias do curso de psicologia, que ao longo da graduação universitária perceberam a invisibilidade racial e feminina nos conteúdos que eram apresentados. Comumente, os autores discutidos eram brancos, não dialogando com a realidade de diversos estudantes e seus contextos sociais. A predominância deste conteúdo unilateral na trajetória universitária levantou reflexões, a exemplo: qual a razão do uso predominante de autores brancos? Qual o papel das negras intelectuais na construção da psicologia? Como os universitários percebem a ausência dessas intelectuais na graduação? Quais os impactos gerados pela ausência de representatividades na trajetória acadêmica de negras e negros universitários?

Paralelo a esses questionamentos, Nascimento (2015) realizou uma pesquisa nas áreas das ciências humanas, exatas e biológicas, para compreender como o protagonismo negro é tratado nesses espaços. $\mathrm{O}$ autor identificou que, apesar da importância da população negra para o desenvolvimento da ciência, o seu reconhecimento foi e prossegue sendo apagado sistematicamente da história. Essa ação pode ser descrita como epistemicídio, segundo Silva e Pinho (2018), uma forma de apagamento dos povos que são secularmente oprimidos, corroborando para a marginalização social que se perpetua na contemporaneidade.

\section{RESUMO}

Apesar da importância da população negra para o desenvolvimento da ciência, o seu reconhecimento foi sendo apagado sistematicamente da história, como um processo de epistemicídio. Este estudo buscou debater a representatividade de negras intelectuais no ensino curricular dos cursos de psicologia. Realizou-se um questionário on-line voltado para profissionais e estudantes de psicologia no qual se indagou questões sobre presença das negras intelectuais nas bibliografias das graduações. Revelou-se a pouca presença de docentes negras nas universidades e nas bibliografias. Os respondentes acessam debates raciais e conteúdos produzidos por cientistas negras em espaços alternativos, como palestras. Essa ausência de representatividade incide na motivação acadêmica e na afiliação universitária. Conclui-se ser importante delinear um ensino de psicologia que contemple saberes expressos por mulheres negras, de modo a romper com posições de inferiorização impostas pela estrutura racial brasileira.

Palavras-chave: Representatividade. Epistemicídio. Negras intelectuais. Ensino de Psicologia. Racismo.

\section{ABSTRACT}

Despite the importance of the black population for the development of science, its recognition has been systematically erased from history. This essay intends to debate the representation of black intellectual women in the curricular teaching of psychology courses. An online questionnaire about the presence of black intellectuals in the bibliographies of undergraduate students was answered by professionals and students of psychology. It was revealed that there was little presence of black professors in universities and in its bibliographies. Respondents access racial debates and content produced by black scientists in alternative sites, such as lectures. This lack of representativeness affects academic motivation and university affiliation. We conclude that it is important to outline a teaching of psychology that contemplates knowledge expressed by black women, in order to break with positions of inferiority imposed by the Brazilian racial structure.

Keywords: Representativeness. Epistemicide. Black intellectuals. Psychology teaching. Racism.

Submetido em: 6 de jul. 2020

Aceito em: 11 de dez. 2020

${ }^{1}$ Centro Universitário Jorge Amado - UNIJORGE, Salvador, Bahia - Brasil.

${ }^{2}$ Universidade do Estado da Bahia - UNEB, Salvador, Bahia - Brasil.

*E-mail para correspondência: pablojacintopsi@gmail.com

Rev. ComCiência - dez. 2020, vol. 5, no. 7, p. 67-76 / doi: 10.36112/issn2595-1890.v5.i7.p67-76 
Apesar do cenário histórico de afastamento dos negros brasileiros do ensino superior e do ambiente acadêmico-científico, observa-se que as ações afirmativas e as políticas sociais, destacando a política de cotas, programas de financiamento e bolsas para estudantes de baixa renda, têm possibilitado o acesso da população negra aos espaços educacionais de nível superior. Recentemente, o Instituto Brasileiro de Geografia e Estatística (IBGE, 2019) divulgou que 50,3\% dos estudantes de graduação nas instituições públicas e privadas são negros (pretos e pardos), contudo, esse número ainda é inferior ao quantitativo de pessoas negras no Brasil, sendo aproximadamente $55 \%$ da população. Esse percentual reduz ao avaliarmos a presença das pessoas negras nos programas de pós-graduação stricto sensu, que segundo o levantamento realizado por Tokarnia (2015), representam apenas $28,9 \%$ do corpo discente. Já na condução dos espaços acadêmicos, exercendo a função de ser professor, o levantamento do G1 com base em dados do Instituto Nacional de Estudos e Pesquisas Educacionais Anísio Teixeira (INEP) constatou que apenas $16 \%$ dos docentes universitários se autodeclararam negros (MORENO, 2018). Portanto, é notória uma sub-representação das pessoas negras em espaços de destaque acadêmico, apesar das recentes políticas sociais de reparação. Quando referido a raça e gênero, notase que a desvantagem é ainda maior, sendo possível percebê-la no cotidiano das universidades. Neste momento não há dados específicos sobre mulheres negras na educação superior, tanto como docente, quanto discente, mas elas continuam sofrendo uma subrepresentação nesta categoria de ensino (CRISOSTOMO; REIGOTA, 2010; CODECO; DIAS, 2018).
Segundo Castelar et al. (2015), as representações do passado e presente do erotismo do corpo da mulher negra constrói uma história contaminada de estereótipos e estigmatização, que contribui com as práticas de preconceito da sociedade. A mulher negra em sociedade de passado escravista, está à mercê especialmente das consequências das discriminações de raça, gênero e classe, constatando a realidade histórica de cerca de 500 anos de desigualdades, 388 destes, de escravidão legal. As mulheres negras vivenciaram de forma diferenciada a sua inserção nos espaços de socialização quando comparadas aos homens negros, e principalmente a mulheres brancas. Nesse sentido, Ferreira e Camargo (2012) afirmam que a negritude é construída em torno de valores considerados socialmente negativos devido ao processo social e histórico de construção do nosso país, marcado pela escravidão das pessoas negras, relacionada à ideia de superioridade racial do branco-europeu.

Segundo Carneiro (2003), desde o período da escravidão as mulheres negras lutam pela conquista da liberdade, enfrentando as violências que eram submetidas. As mulheres negras têm sido por cerca de quinhentos anos de história brasileira as maiores vítimas da desigualdade racial. Suas pautas são invisibilizadas pelo viés eurocentrista do feminismo, que engloba as mulheres a partir de uma única característica em comum: o gênero, preterindo as discussões de raça e privilegiando as pautas que contemplam apenas as mulheres brancas.

A mulher negra é afetada diretamente pela intersecção, contrapondo a redução da categoria mulher a uma única identidade. A interseccionalidade visa a compreensão do entrelaçamento das múltiplas identidades, como raça, gênero, classe e sexualidade (CRENSHAW, 2004; RIBEIRO, 2019). Portanto, mulheres negras não são afetadas da mesma forma que as mulheres brancas, logo, ocupa um lugar social em que a mulher negra torna-se "o Outro do Outro", sendo a sua existência ainda mais vulnerável (KILOMBA, 2019). A experiência das mulheres negras no mercado de trabalho é um dos exemplos que demonstram essas desigualdades, o retrato do índice de desigualdade raça/gênero dos últimos vinte anos apresentados pelo IPEA (2011) são utilizados como referência. No Brasil, ocupando a profissão de empregada doméstica, cerca de $21 \%$ são mulheres negras, enquanto $12,5 \%$ delas são brancas. Entre elas, apenas $23 \%$ das mulheres negras possuem carteira de trabalho assinada, enquanto $30 \%$ das brancas possuem o registro. Outro dado importante é referente a média salarial, segundo os dados do IBGE (2003) as mulheres negras possuem renda média mensal de $\mathrm{R} \$ 279,70$; os homens negros $\mathrm{R} \$$ 428,30 ; as mulheres brancas $\mathrm{R} \$$ 554,60 e; os homens brancos de $\mathrm{R} \$$ 931,10. Esses números apontam as desigualdades de raça e gênero no Brasil, sendo possível perceber como a mulher negra encontra-se em situação de maior vulnerabilidade, o que se estende para outros contextos, incluindo o acadêmico, onde há ausência de estímulos sociais para sua inserção e permanência nos diversos níveis educacionais (SILVA JR., 2002).

Nesse sentido, faz-se uma reflexão: como uma pessoa negra se torna um(a) intelectual no Brasil? A norma do branqueamento se traduz nas diversas esferas da sociedade brasileira de forma sistemática e promove uma hierarquização dos indivíduos que também é reproduzida nos ambientes universitários (SANTOS FILHO, 
2020). Observa-se que o branqueamento é também um processo histórico de caráter ideológico, que Carone e Bento (2012) demonstraram fazer parte do projeto brasileiro. Excluir as produções culturais e intelectuais da população negra reforça um apagamento desse povo e serve a um ideal de país embranquecido, que reproduz diversas expressões do sistema colonial.

Ratts (2007) é um dos autores que apresentam discussões relacionadas a exclusão das produções e participação das negras intelectuais nos espaços:

Os intelectuais brancos, que não deixam de ser atuantes (ou mesmo "ativistas") em seus campos de pesquisa/intervenção, fazem desse circuito próximo suas redes profissionais. Promovem uns aos outros, citam-se mutuamente em seus escritos. Criam ou elegem para si fechados espaços acadêmicos e quase nunca evidenciam a branquitude que os amalgama, ainda que se aproximem de um(a) ou outro(a) intelectual negro(a) (p.30).

$\mathrm{O}$ autor prossegue afirmando que, quanto à invisibilidade do negro na academia brasileira, há uma barreira racial e étnica que se manifesta na baixa presença de homens e na frequente ausência de mulheres negras no corpo discente e consequentemente docente. A intelectualidade acadêmica brasileira hegemônica dificulta e silencia o reconhecimento do sujeito negro, mulher ou homem, como produtora de pensamentos, ampliando os mecanismos da "invisibilidade negra" através da reprodução de uma lógica estrutural. Segundo Hooks (2013) o apagamento de negras intelectuais é fruto do silenciamento histórico imposto pela escravidão, pelo racismo, sexismo e a desigualdade de classe. Carneiro
(2005) ressalta que esse processo epistemicida tem conexão com a tecnologia do biopoder, delimitando lugares sociais a serem ocupados pelas mulheres negras, excluindo-as do campo acadêmico.

À mulher negra são negados os espaços de formação e principalmente de exercício acadêmico. Essa negação reflete a ausência de mulheres negras apresentadas nas figuras de intelectuais nas universidades, e isso impacta diretamente na formação dos negros e negras universitárias. Rosa (2017) ressalta a importância dessa representatividade na formação identitária no meio acadêmico, que é apontado como um espaço de competitividade e desafios aos negros. Segundo Santos Filho (2020), é nesse contexto que alguns negros universitários constroem uma identidade racial, traçando estratégias de resistência e enfrentamento para permanecer em um ambiente predominantemente branco. Estudos recentes revelam o quanto jovens de camadas populares, predominantemente negros, enfrentam maiores problemáticas ao longo da graduação (OLIVEIRA; ROSA, 2015; LEMOS, 2017). Esses desafios se agravam quando os cursos se apresentam como de "alto prestígio" (OLIVEIRA, 2017; SILVA, 2018). Os estudos citados apontam que os desafios se estendem entre questões relacionadas à pobreza e dificuldade de acesso a bens e serviços necessários para a conclusão da graduação e problemas relacionais explicitamente marcados pelo racismo institucional, que interfere na interação entre estudantes negros e não-negros, bem como nas relações entre estudantes negros, professores e coordenadores.

Coulon (2017) destaca que, mesmo na realidade francesa, cuja democratização do ensino superior é praticada desde a década de 1960 , as taxas de abandono geral na graduação são elevadas, chegando a $30 \%$. Dos que permanecem, grande parte não conclui a graduação no período mínimo estipulado. $\mathrm{O}$ autor delineou a condição que nomeou de "ofício do estudante" para apresentar os enfrentamentos que são elencados pelos estudantes na busca por afiliação à realidade universitária. Dentre os desafios, incluem-se: mudança do modelo pedagógico em relação ao ensino médio, novas rotinas, regras específicas das instituições de ensino superior, e um leque de atribuições tácitas necessárias para o bom exercício da graduação, extrapolando as demandas explicitadas pelos docentes. Através do processo de afiliação, que tende a ocorrer gradualmente conforme o estudante se apropria desses elementos, ele torna-se um membro da comunidade acadêmica.

A afiliação, entretanto, não é um processo homogêneo. Ele engloba características específicas de cada realidade institucional em contraponto com aspectos relacionados ao perfil de cada estudante. Na busca por fazer-se membro da universidade, o estudante exerce uma dialética que engloba também como a comunidade acadêmica acolhe e propicia o seu desenvolvimento. Nesse sentido, a condição racial, associada à etnia, gênero, classe social ou sexualidade, delineia obstáculos para o estudante em sua trajetória de afiliação universitária.

Figueiredo (2018) pontua que jovens de camadas populares frequentemente possuíram uma trajetória na educação básica do ensino público que não os preparam para as rotinas de estudo demandadas na graduação. A condição de renda interfere também nas relações interpessoais com outros colegas, pois há estudantes que evitam participar de confraternização por falta de recursos. Outra marca apontada é a 
dificuldade apresentada por alguns pais em apoiarem a longevidade da vida escolar, pela expectativa de uma inserção dos filhos no mercado de trabalho após a conclusão do ensino médio, já que o retorno financeiro pode se apresentar de forma emergencial em famílias socioeconomicamente vulneráveis. Já Silva (2018), acompanhando estudantes socioeconomicamente vulneráveis no curso de medicina da Universidade Federal da Bahia, destaca que esses jovens apresentam um itinerário para alcançar o ensino superior que contrapõe-se à naturalidade do avançar acadêmico vivenciada por estudantes ricos. Aos representantes de camadas populares, frequentemente não há histórias de referência em suas famílias e aqueles que alcançam o ensino superior trilham uma trajetória completamente nova em seus contextos, sendo geralmente os primeiros a alcançarem tal feito. A autora ressalta que esses estudantes são tensionados a criarem estratégias para superar os desafios materializados na graduação, seja pela falta de recursos para investir em materiais exigidos pelas disciplinas, ou pelos constantes discursos de desvalorização e desestímulo proferido por professores e colegas.

Os estudantes cotistas compõem majoritariamente a classe popular inserida no ensino superior (BRUNO; NASCIMENTO, 2019). Com destaque a essa condição, os autores ressalvam que os estudantes cotistas adentraram a universidade em meio a um discurso universalista, que prega um acesso amplo ao ensino superior, porém sem a execução de práticas realmente universalistas. Para Gonçalves e Ambar (2015), ao adentrar a universidade, o estudante negro é empurrado a assumir dois posicionamentos: adotar os códigos dos brancos, de modo a inserir-se melhor nos meandres institucionais, ou entrar em embate contra as manifestações do racismo nesse meio. A segunda alternativa é acompanhada do desgaste, pois as bases do racismo estrutural que sustentam as práticas institucionais na academia seguem firmadas por práticas e normas seculares.

Desse modo, as trajetórias de cotistas no ensino superior seguem marcadas por: dificuldades financeiras que limitam o acesso a materiais de ensino; demérito quanto ao direito de estar no espaço universitário, diante de julgamentos contrários às cotas (LEMOS, 2017); descrédito quanto à capacidade de racionalização da pessoa negra, o que exige maior esforço desses estudantes para alcançar o reconhecimento que buscam (ALCANTARA; NASCIMENTO, 2018; OLIVEIRA; ROSA, 2015); e, especialmente, falta de representatividade nas figuras de êxito intelectual, como professoras(es) ou autoras(es) (BRUNO; NASCIMENTO, 2019). Tem-se, aí, algumas das barreiras a serem enfrentadas no processo de afiliação que demarcam precisamente o lugar do estudante cotista como um espaço diferenciado, passível de embates por fugir à suposta normalidade do percurso acadêmico.

Santos e Silva (2011), entretanto, convidam a uma reflexão sobre como compreendemos as trajetórias escolares no ensino superior. Para as autoras, estudantes cotistas não devem ser alçados ao lugar da evasão, no discurso científico, pois - mesmo diante das dificuldades - têm majoritariamente evoluído no cenário universitário. Dados como notas ou duração média para a conclusão da graduação podem não representar os alcances acadêmicos que essa parcela de estudantes atinge. Ademais, tende-se a transferir para eles - reificados na sua condição socioeconômica - a respon- sabilidade por não conseguirem aproveitar integralmente a graduação, deixando de lado a função das políticas de permanência e o próprio racismo institucional que as escassa. $\mathrm{O}$ fato é que a universidade cada vez mais recebe pessoas negras ocupando suas cadeiras e as tensões geradas por essa heterogeneização não esperada pela construção elitista dos espaços universitários ainda estão sendo desveladas.

Na busca de uma educação antirracista, essa pesquisa teve como objetivo analisar a presença e representatividade de negras intelectuais na historiografia obrigatória e complementar do curso de Psicologia. Reconhecendo, assim, a necessidade de aprofundar a discussão sobre a invisibilidade de negras intelectuais no contexto acadêmico proveniente das situações de epistemicídio e entender como a valorização da diversidade relevante para os sujeitos.

\section{MÉTODO}

Esse estudo de levantamento tem caráter descritivo e utilizou como procedimento de produção de dados um questionário on-line através do Google Forms. Esse instrumento foi divulgado para estudantes e profissionais oriundos do curso de psicologia de instituições de ensino superior, públicas e privadas da Bahia. Houve predominância de respondentes baianos, porém foram identificadas respostas de outros estados (Rio de Janeiro, São Paulo e Minas Gerais), que foram consideradas válidas, não interferindo nos resultados, obtendo respostas semelhantes e oferecendo brechas para expandir o estudo à nível nacional, visto que, o fenômeno das relações racialis corresponde a todo território brasileiro. $\mathrm{O}$ questionário esteve aberto ao longo do mês de agosto de 2019 e 
encerrado quando obteve respostas suficientes para a análise pretendida.

Os dados quantitativos coletados foram analisados a partir do Excel, que auxiliou na construção de gráficos e tabelas para facilitação do processo de interpretação dos resultados. Para as respostas abertas, utilizou-se procedimentos da análise de conteúdo (BARDIN, 2011), permitindo a categorização dos discursos das pessoas entrevistadas.

Este trabalho está em consonância com seguindo as Resoluções $n^{\circ}$ 466/12 e $\mathrm{n}^{\circ}$ 510/2016 do Conselho Nacional de Saúde, englobando os Critérios da Ética em Pesquisa com seres humanos, tendo a aprovação de todas as estudantes, através do Termo de Consentimento Livre e Esclarecido.

\section{RESULTADOS E DISCUSSÕES}

Após a aplicação do instrumento, foram obtidas 70 respostas. Dentre estas, 50 foram de estudantes, e 20 de profissionais formados em psicologia. Entre eles, 19 se declaram pretos, 9 pardos, 5 brancos e 2 amarelos, os outros 35 não responderam. Dos respondentes, 35 pessoas não declararam sua filiação institucional, 30 informaram ser oriundos de instituições privadas e 05 de instituições públicas. Entre os estudantes, a maioria $(52 \%)$ está prestes a concluir a graduação, sendo 26 dos três últimos semestres, o oitavo, nono e décimo. Entre os 20 profissionais, apenas 5 têm entre 20 e 30 anos de formados, 1 tem 7 anos de formação, e os demais formaram-se dentro dos últimos 3 anos.

Entre as perguntas, questionouse acerca da presença de docentes negras na graduação. 42 respondentes (60\%) revelaram ter tido docentes negras, enquanto 28 (40\%) não tiveram contato com esse perfil. Em con- trapartida, quanto à presença de autoras negras na historiografia obrigatória das disciplinas, apenas $6(9 \%)$ lembram ter tido acesso ao conteúdo. $\mathrm{Ou}$ seja, apesar da presença de professoras negras nos quadros institucionais, os recursos adotados seguem contemplando majoritariamente personalidades brancas. Apesar da inserção dos negros no ambiente acadêmico, as autoras negras permanecem invisibilizadas, evidenciando a reprodução do racismo estrutural no ambiente institucional. Outra possibilidade que explica esse dado é a não explanação da condição racial dos autores estudados, o que impossibilita os alunos negros de conhecerem intelectuais que se aproximem das suas realidades.

Cerca de $24 \%$ dos entrevistados responderam que tiveram acesso a autoras negras na historiografia complementar das disciplinas. Isso pode significar que as(os) docentes mencionam ou abordam de modo mais superficial materiais produzidos por autoras negras. Entretanto, ao falar sobre as bibliografias básicas das disciplinas da grade de progressão linear, os índices destoam dos dados apresentados, dando ênfase ao debate da invisibilidade de negras intelectuais, assim como, do epistemicídio racial na graduação em psicologia. Aos estudantes, foi perguntado sobre quantas e quais intelectuais eles conheceram, entre as respostas, apenas 15 recordaram o nome de alguma autora negra.

Entendendo que o conhecimento na universidade é construído nas distintas relações estabelecidas, não ficando restrito à transmissão entre professor e aluno, foi possível perguntar as pessoas entrevistadas se elas tiveram contato com produções de autoras negras ao longo do curso de psicologia. Do total, cerca de $31,4 \%$ disseram que sim e $68,6 \%$ permanece- ram sem ter visto autoras negras na graduação. No que diz respeito a outros meios de discussão sobre a temática, como fórum, palestras, rodas de conversas e debates cerca de $80 \%$ assinalaram uma ou mais alternativas de espaços onde tiveram contato com a temática.

Enquanto nos espaços institucionalizados a reprodução do conhecimento aceito pela branquitude ganha corpo, percebe-se que os estudantes acessam outros espaços com o objetivo de formar novas perspectivas que distinguem dos moldes submetidos no ambiente acadêmico. Congressos, fóruns, seminários e outros espaços de discussão, são ambientes que possibilitam o contato com saberes produzidos por pessoas negras, sendo importante ferramenta para o reconhecimento do negro universitário em seus processos de afiliação.

As respostas reafirmam a noção do epistemicídio e a exclusão dos conhecimentos produzidos pelos negros, revelando como os grupos dominantes mantém uma seleção teórica a ser abarcada pelas grades curriculares.

Sobre isso, Carneiro (2005) afirma:

Para nós, porém, o epistemicídio é, para além da anulação e desqualificação do conhecimento dos povos subjugados, um processo persistente de produção da indigência cultural: pela negação ao acesso à educação, sobretudo de qualidade; pela produção da inferiorização intelectual; pelos diferentes mecanismos de deslegitimação do negro como portador e produtor de conhecimento e de rebaixamento da capacidade cognitiva pela carência material e/ou pelo comprometimento da autoestima pelos processos de discriminação correntes no processo educativo. Isto porque não é possível desqualificar as formas de conhecimento dos povos 
dominados sem desqualificá-los também, individual e coletivamente, como sujeitos cognoscentes. E, ao fazê-lo, destituilhe a razão, a condição para alcançar o conhecimento "legítimo" ou legitimado. Por isso o epistemicídio fere de morte a racionalidade do subjugado ou a sequestra, mutila a capacidade de aprender etc. (p. 97).

Durante a trajetória das negras universitárias na graduação, é possível perceber a reprodução de narrativas raciais repletas de estereótipos, gerando questionamentos sobre o lugar de discente poder ser ocupado por mulheres negras. Foi possível considerar o lugar histórico que os antepassados negros ocuparam na psicologia brasileira, quase sempre na figura de objetos de estudo, por vezes, servindo de base para afirmações arraigadas de pensamentos racistas, como nas narrativas de Nina Rodrigues em seus estudos sobre raça e responsabilidade penal no Brasil (NEVES, 2008). As mulheres negras aprendem desde a infância que o direito de fala é um privilégio branco, e as instituições de ensino superior reproduzem esse estereótipo social dentro da academia, reafirmando o pensamento da branquitude como produção do saber.

Nesse sentido, Carneiro (2005) fala que o branco representa todos os aspectos positivos e de ascensão dentro da lógica acadêmica que permeia a ciência brasileira, enquanto o negro segue assimilado a todas as expressões negativas, inclusive a de categoria intelectualmente inferior. A história social de ascensão do negro brasileiro é, assim, a história de sua assimilação aos padrões brancos de relações sociais, pois reivindicar a cultura branca e negar a cultura negra foi um ato para a conquista de espaços sociais menos aviltados (CARONE; BENTO, 2012).
Nesta pesquisa, se perguntou sobre a ausência de intelectuais negras e se isso afetou as suas trajetórias na graduação. Do total, $80 \%$ afirmaram sentir-se afetados, $12 \%$ afirmaram não terem se sentido afetados e $8 \%$ não responderam. Essa pergunta teve um complemento em que era necessário responder sobre os impactos da ausência de negras intelectuais em seu cotidiano acadêmico. Parte dos estudantes afirmaram "não terem parado para pensar sobre o assunto". Almeida (2019) ajuda a compreender este resultado ao dizer que:

Todas essas questões só podem ser respondidas se compreendermos que o racismo, enquanto processo político e histórico, é também um processo de constituição de subjetividade, de indivíduos cuja consciência e afetos estão de algum modo conectados com as práticas sociais. Em outras palavras o racismo só consegue se perpetuar se for capaz de: 1. Produzir um sistema de ideias que forneça uma explicação "racional" para a desigualdade racial; 2. Construir sujeitos cujos sentimentos não sejam profundamente abaladas diante da discriminação e da violência racial e que considerem "normal" e "natural" que no mundo haja "brancos" e "não brancos" (p. 63).

Essas respostas trazem em evidência o racismo enquanto processo de construção de subjetividades, no qual parte dos indivíduos sequer se sente afetada pela negação do acesso à negras intelectuais e conteúdos por elas produzidos. A não racialização acerca da ausência de negras intelectuais na graduação também é problemática, pois revelam a naturalização da violência racial que subjaz esse apagamento, não ganhando sequer espaço para questionamentos. Entende-se, que o racismo compõe a estrutura da soci- edade brasileira e segue presente perpetuando um projeto políticoideológico ainda dominante (SANTOS FILHO, 2019).

Contrapartida, os dados apresentam uma maioria que revelam ter questionado a falta de representatividade e afirmam não se sentirem representados pelo conteúdo curricular apresentado. Essas respostas refletem o pensamento de Rosa (2017), que fala sobre a permanência e a importância não apenas de ocupar a cadeira de graduando, mas sentir-se representado pelo contexto em que se encontra, influenciando diretamente em seus processos de afiliação ao ambiente universitário.

As respostas obtidas revelam o epistemicídio, representado pela não validação do conhecimento do negro. A experiência de estar em um lugar sem sentir-se pertencente foi afirmada nas respostas, com a expressão "estar no lugar errado". É possível que o reconhecimento em relação aos componentes curriculares de negras intelectuais, assim como a expressão destes em sala de aula, influenciam nos processos de afiliação e permanência dos estudantes. Devido às dificuldades enfrentadas, estudantes negros precisam estar se reafirmando intelectualmente em diversos momentos, para permanecer em um espaço pertencente à branquitude, e como consequência, esses estudantes podem apresentar impactos negativos em sua saúde mental. A psicologia como um campo voltado aos cuidados e promoção de saúde mental, precisa dialogar com a diversidade, e os docentes devem considerar o papel do processo ensinoaprendizagem na construção identitária do sujeito negro. Entretanto, apesar de haver representantes negras na trajetória da psicologia brasileira, como Virgínia Bicudo, Neuza Santos, Isildinha 
Nogueira, Jeane Tavares, Luciene Lacerda, dentre outras autoras contemporâneas, essas são pouco abordadas, principalmente nos estudos não referidos às relações raciais.

Em uma de suas palestras no Brasil, Grada Kilomba apresenta falas que propõe a descolonização do pensamento e a quebra de paradigmas. A autora questiona os espaços de fala, assim como, quem pode falar e quem não pode falar no cenário acadêmico, refletindo sobre a presença de negras intelectuais na base curricular, e a voz do graduando negro na universidade. Segundo Kilomba (2016) mesmo quando possui espaço para expressar suas ideias, o intelectual negro reflete sobre o que pode ser dito, nos ambientes que ocupa. Com isso, questiona:

[..] qual conhecimento é reconhecido como tal? E qual conhecimento não o é? Qual conhecimento tem feito parte das agendas e currículos oficiais? E qual conhecimento não faz parte de tais currículos? A quem pertence este conhecimento? [...] quem é reconhecido/a como alguém que tem conhecimento? E quem, não é? Quem pode ensinar conhecimento? Quem pode produzir conhecimento? Quem pode performá-lo? E quem não pode? (p. 5-6).

A trajetória desta pesquisa apresenta respostas para essas indagações. As negras intelectuais têm sido negligenciadas na formação em psicologia e os estudantes negros majoritariamente reconhecem os impactos que esse epistemicídio proporciona. Para Ribeiro (2019) pensar uma epistemologia que inclui mulheres negras apresenta reflexos práticos na trajetória estudantil:

O termo é composto pela palavra grega episteme, que significa conhecimento, e logos, que significa ciência. Epistemologia é, então, a ciência da aqui- sição de conhecimento, que determina: 1. (Os temas) quais temas ou tópicos merecem atenção e quais questões são dignas de serem feitas com o intuito de produzir conhecimento verdadeiro. 2. (os paradigmas) quais narrativas e interpretações podem ser usadas para explicar um fenômeno, isto é, a partir de qual perspectiva o conhecimento verdadeiro pode ser produzido. 3. (os métodos) e quais maneiras e formatos podem ser usados para a produção de conhecimento confiável e verdadeiro (p. 4950).

A forma como o conhecimento é projetado e as bases epistemológicas reproduzidas no ambiente acadêmico, traçam as possibilidades de construção de métodos e formas de construir um ideal de saber.

Ao serem questionados como interpretam a importância de negras intelectuais em sua formação, os entrevistados utilizaram expressões como: representatividade, importância, relevância, enriquecimento. Aparecem também falas que expressam inquietudes e desconfortos que as levaram à busca por autoras negras. É possível reconhecer que as inquietações pessoais e a percepção das vivências singulares de negritude impulsionou o contato de diversos estudantes com autoras negras. Esse contato é expresso em falas que reconhecem o fator racial atrelado à diversas expressões da subjetividade, como o Estudante 46, que diz: "O racismo causa marcas de sofrimento geracionais que precisam ser contextualizadas na clínica a nível de saúde pública da população negra" e a Estudante 48 que fala sobre a autopercepção: "Já que somos vistos somente como mão de obra de pouco inteligência, o conhecimento sobre essas intelectuais eleva minha autoestima”.
Com essas falas, é possível perceber que o contato com a produção epistêmica de negras intelectuais produz novos acessos ao conhecimento das práticas psicológicas, assim como novas formas de representação dos corpos negros, gerando mudanças em sua autopercepção e também uma elevação da autoestima.

Moreira (2019) relata que o racismo é algo presente em símbolo, que não precisa ser colocado em palavras, todos entendem, é cultural, faz parte de um sistema muito bem estruturado, que foi e é mantido para sustentar o lugar do grupo dominante, e impossibilitar que os grupos minoritários tenham acesso a esse lugar que é de privilégio do branco, para que o mesmo se mantenha hegemônico. O Autor afirma, que:

Isso faz com que a cultura, os padrões estéticos e as práticas de poder de um determinado grupo tornem-se o horizonte civilizatório do conjunto da sociedade. Assim, o domínio de homens brancos em instituições públicas - o legislativo, o judiciário, o ministério público, reitorias de universidades etc. - e instituições privadas - por exemplo, diretoria de empresas - depende, em primeiro lugar, da existência de regras e padrões que direta ou indiretamente dificultem a ascensão de negros e/ou mulheres, e, em segundo lugar, da inexistência de espaços em que se discuta a desigualdade racial e de gênero, naturalizando, assim, o domínio do grupo formado por homens brancos (p. 41-42).

Moreira (2019) prossegue afirmando que o domínio da branquitude em espaços institucionais permite que eles se defendam, e se protejam de qualquer conflito que ameace esse poder. É uma forma de resistir a qualquer tentativa dos grupos e indivíduos minoritários de ascensão nesses espa- 
ços, como também de negar a existência do racismo, e omitir atos de violência raciais, além de garantir o controle econômico e político da sociedade.

O racismo é entendido como estrutural, e perpassa diversas áreas sociais, de forma individual e coletiva, presente no cotidiano e visto de forma natural, ocorrendo "pelas costas dos indivíduos e lhes parece legado pela tradição" (ibidem, p. 31). Fala-se de um sistema que provoca desigualdades econômicas, políticas, jurídicas e como percebido, nos ambientes acadêmicos. Construir espaços para debater sobre raças, gêneros, classes e sexualidades é fundamental, através disto é possível perceber as diferenças sociais brasileiras e construir novas estratégias de reorganização de um racismo que é estrutural.

\section{CONSIDERAÇÕES FINAIS}

A discussão apresentada perpassa a problematização levantada acerca da escassez e invisibilidade em que se encontram as negras intelectuais no cenário acadêmico da psicologia. A partir dos dados coletados através da presente pesquisa, considerando as articulações teóricas desenvolvidas, foi constatada a baixa representatividade da mulher negra, que apesar de presente nos corpos docente e discente, não foram apresentadas nas bibliografias obrigatórias e complementares dos cursos de psicologia de onde provinham os respondentes.

Destaca-se que prática educativa é um exemplo da negação histórica da existência pensante de nãoeuropeus. Entender a construção do conhecimento a partir dessa perspectiva é uma prática decolonial, como forma de emancipar-se do pensamento eurocêntrico, pois oferece alternativas à escrita epistêmica mantida pela elite branca que por vezes não atingem as demandas subjetivas da população negra.

Constatamos também o impacto dessa não representação na trajetória dos estudantes e profissionais. Foram identificadas respostas acerca dos efeitos do racismo estrutural, incluindo a naturalização da ausência de figuras representativas de mulheres negras. Observou-se que no cenário pesquisado se instaura um sistema onde está demarcado quem pode e quem não pode falar, quem tem ou não o conhecimento, evidenciando o epistemicídio.

Esses têm efeitos diretos na vida acadêmica e pessoal dos mesmos, sinalizando o adoecimento psíquico e a baixa motivação acadêmica relacionadas a uma propagação, mesmo dentro da academia, dos estereótipos socialmente negativos do negro.

Diante disso reconhecendo a necessidade de rever a prática educativa atualmente no Brasil bem como refletir sobre diferenças entre grupos, buscando romper com os estereótipos que nos foi imposto, situações de exclusão e de invisibilidade. Constatouse a presença do epistemicídio dos saberes provenientes de cientistas mulheres negras no espaço acadêmico dos cursos de psicologia. Conclui-se que há importância da representatividade da mulher negra no contexto acadêmico.

\section{REFERÊNCIAS}

ALCANTARA, I. L. S.; NASCIMENTO, C. O. C. Produção de conhecimento na universidade e trajetória acadêmica de estudantes negros(as). In: Congresso Brasileiro de Pesquisadores Negros: (Re) Existência Intelectual Negra e Ancestral - 18 anos de enfrentamento. Uberlândia. Anais. Uberlândia: COPENE, 2018.

ALMEIDA, S. L. Racismo Estrutural.
Editora Jandaíra, 1ª ed. São Paulo, 2019.

ASSIS, D. N. C. de. Corpos negros e representação social no Brasil: uma discussão de gênero e raça. In: Revista da ABPN, v. 9, n. 21, páginas 123 - 134. Nov. 2016 - fev. 2017. Disponível em: $<$ http://abpnrevista.org.br/revista/index.p hp/revistaabpn1/article/view/231> Acesso em: 10 de mai. 2019.

BARDIN, L. Análise de Conteúdo. São Paulo: Edições 70, 2011.

BRUNO, J. S.; NASCIMENTO, C. O. C. Desafios para a equidade racial nas universidades: os processos de continuidade da colonização na esfera epistemológica de formação. Revista Internacional Interdisciplinar INTERthesis, Florianópolis, v. 16, n. 1, p. 1634, fev. 2019. ISSN 1807-1384. Disponível em:

<https://periodicos.ufsc.br/index.php/i nterthesis/article/view/1807-

1384.2019v16n1p16>. Acesso em: 28

de jun. 2020. doi:

https://doi.org/10.5007/1807-

1384.2019v16n1p16.

CARNEIRO, S. Mulheres em movimento. Estud. Av., São Paulo, v. 17, n. 49, páginas 117 - 133, 2003. Disponível em

$<$ http://www.scielo.br/scielo.php?s cript=sci_arttext\&pid=S0103-

40142003000300008\&lng=en\&nr $\mathrm{m}=$ iso $>$ Acesso em: 13 de mai. 2019.

CARNEIRO, S. A construção do outro como não-ser como fundamento do ser. São Paulo: Universidade de São Paulo, tese de doutoramento, 2005.

CARONE, I; BENTO, M. A. S. Psicologia social do racismo: estudos sobre branquitude e branqueamento no Brasil. Petrópolis: Editora Vozes, 2012.

CASTELAR, M. et al. Brinquedos e brincar na vida de mulheres educadoras negras. Psicol. Esc. Educ. Maringá, v.19, n.3, p.595 - 602, dez. 2015. Disponível em:

<http://www.scielo.br/scielo.php?script= 
sci_arttext\&pid=S1413-

$85572015000300595 \& \operatorname{lng}=p t \& n r m=$ iso $>$ Acesso em: 14 de mai. 2019.

CODECO, C. T.; DIAS, C. M. Mulheres na ciência. Cad. Saúde Pública,

Rio de Janeiro, v. 34, n. 10, e00173718, 2018. Disponível em: <http://www.scielo.br/scielo.php?scrip $\mathrm{t}=$ sci_arttext\&pid=S0102-

311X2018001000101\&lng=en\&nrm=i so>. Acesso em: 23 jan. 2020. Epub

Oct 11, 2018.

http://dx.doi.org/10.1590/0102$311 \times 00173718$.

COULON, A. O ofício de estudante: a entrada na vida universitária. Educ. Pesqui., São Paulo, v. 43, n. 4, p. 1239-1250, dez. 2017. Disponível em:

$<$ http://www.scielo.br/scielo.php?scrip $\mathrm{t}=\mathrm{sci}$ arttext\&pid=S1517-

$97022017000401239 \& \operatorname{lng}=$ pt\&nrm $=$ is o>. Acesso em: 28 jun. 2020.

http://dx.doi.org/10.1590/s15179702201710167954.

CRENSHAW, K. A interseccionalidade na discriminação de raça e gênero. VV. AA. Cruzamento: raça e gênero. Brasília: Unifem, 2004.

CRISOSTOMO, M. A. S.; REIGOTA, M. A. S. Professoras universitárias negras: trajetórias e narrati-

vas. Avaliação (Campinas), Sorocaba, v. 15, n. 2, p. 93-106, jul. 2010.

Disponível em:

<http://www.scielo.br/scielo.php?scrip $\mathrm{t}=$ sci_arttext\&pid=S1414-

40772010000200005\&lng=en\&nrm=is o>. Acesso em: $28 \mathrm{de}$

jun. 2020. https://doi.org/10.1590/S14 14-40772010000200005.

CUSTÓDIO, M. S. Mulher negra: Da inserção na história a inserção na propaganda. Revista de Iniciação Científica da FFC, v. 5, n. 1/2/3, páginas 37-49, 2005.

FERREIRA, R. F.; CAMARGO, A. C As relações cotidianas e a construção da identidade negra. Psicol. cienc. prof., Brasília, v. 31, n. 2, p. 374-389, 2011. Disponível em:
$<$ http://www.scielo.br/scielo.php?scrip

$\mathrm{t}=$ sci_arttext\&pid=S1414-

$98932011000200013 \& \operatorname{lng}=\mathrm{en} \& \mathrm{nrm}=$ is o>. Acesso em 28 de

jun. 2020. https://doi.org/10.1590/S14 14-98932011000200013.

FIGUEIREDO, A. C. Limites para afiliação à vida acadêmica de estudantes de camadas populares no contexto de expansão universitária. Educ. Pesqui., São Paulo, v. 44, e173462, 2018.

Disponível em:

$<$ http://www.scielo.br/scielo.php?scrip $\mathrm{t}=$ sci_arttext\&pid=S1517-

$97022018000100312 \& \operatorname{lng}=\mathrm{en} \& \mathrm{nrm}=$ is o>. Acesso em: 28 de jun. 2020.

Epub jul. 19, 2018.

http://dx.doi.org/10.1590/s1678-

4634201844173462.

GIACOMINI S, M. Mulher e escrava, uma introdução histórica ao estudo da mulher negra no Brasil. Local: Vozes, 1988.

GONÇALVES, R.; AMBAR, G.A questão racial, a universidade e a (in)consciência negra. Lutas Sociais, São Paulo, vol.19 n.34, p.202-213, jan./jun. 2015.

HOOKS, B. Ensinando a transgredir: a educação como prática da liberdade. São Paulo, Martins Fontes, 2013.

HOOKS, B. Intelectuais negras. Disponível em:

<https://www.geledes.org.br/wpcontent/uploads/2014/10/16465-50747-1PB.pdf> Acesso em: 08 de set. 2019.

\section{INSTITUTO BRASILEIRO DE GE-} OGRAFIA E ESTATÍSTICA. Desigualdades Sociais por Cor ou Raça no Brasil. Estudos e Pesquisas. Informação Demográfica e Socioeconômica, n.41, 2019. Disponível em:

<https://biblioteca.ibge.gov.br/visualiz acao/livros/liv101681_informativo.pdf >. Acesso em: 20 de jun. 2020.

INSTITUTO BRASILEIRO DE GEOGRAFIA E ESTATÍ́STICA. Pesquisa Nacional por Amostra de Domicílios 2003. Rio de Janeiro: IBGE, 2003. Disponível em: <http://www.ibge.gov.br/home/estatist ica/populacao/trabalhoerendimento/pn ad2003/default.shtm>. Acesso em: 21 de jun. 2020.

INSTITUTO DE PESQUISA ECONÔMICA APLICADA. Retrato das desigualdades de gênero e raça. $4^{\mathrm{a}}$ ed. Brasília: Ipea, 2011.

\section{KILOMBA, G. Descolonizando o} conhecimento - uma palestra performance. Trad. Jessica Oliveira. 2016.

KILOMBA. G. Memórias da plantação: Episódios de racismo cotidiano. Tradução: Jess Oliveira. - $1^{\mathrm{a}}$. ed. - Rio de Janeiro: Cobogó, 2019.

LEMOS, I. B. Narrativas de cotistas raciais sobre suas experiências na universidade. Rev. Bras. Educ., Rio de Janeiro, v. 22, n. 71, e227161, 2017. Disponível em:

$<$ http://www.scielo.br/scielo.php?scrip $\mathrm{t}=$ sci_arttext\&pid=S1413-

24782017000400226\&lng=en\&nrm=is o>. Acesso em: 23 de jan. 2020.

MOREIRA, A. J. Racismo Recreativo. São Paulo, Sueli Carneiro; Pólen, 2019.

MORENO, A. C. Negros representam apenas $16 \%$ dos professores universitários. G1. 20 de novembro de 2018. Disponível em:

$<$ https://g1.globo.com/educacao/guiade-

carreiras/noticia/2018/11/20/negros-

representam-apenas-16-dosprofessores-universitarios.ghtml>. Acesso em: 21 de jun.2020.

NASCIMENTO, A. Intelectuais negros estão fora da bibliografia, criticam especialistas. Entrevista cedida a: Mariana Takarnia. Agência Brasil, Brasília, 2015. Disponível em: < https://www.ebc.com.br/educacao/201 5/05/intelectuais-negros-estao-fora-dabibliografia-criticam-especialistas $>$. Acesso em 30 de jun. 2020.

NEVES, M. A concepção de raça humana em Raimundo Nina Rodrigues.

Filosofia e História da Biologia, v. 3, 
2008, p. 241-261.

OLIVEIRA, S. S. Afiliação universitária: trajetórias de estudantes cotistas e não cotistas em cursos de alto prestígio social na Universidade Federal da Bahia. Dissertação (Mestrado em Educação) - Faculdade de Educação, Programa de Pós-Graduação Em Educação, Universidade Federal da Bahia. Bahia, p. 162. 2017.

OLIVEIRA, S. S.; ROSA, D. L. Afiliação universitária de estudantes cotistas e não cotistas: abordagens iniciais no âmbito dos aportes teóricos. Equidade no ensino superior, 18 de novembro de 2015. Disponível em: < http://www.equidade.faced.ufba.br/site s/equidade.oe.faced.ufba.br/files/artigo _afiliacao_estudantes_cotistas_e_nao_ cotistas.pdf $>$. Acesso em: 21 de jun. 2020 .

PINHEIRO, L.; SOARES, V. Brasil: retrato das desigualdades - gênero, raça. Ipea - Instituto de Pesquisa Econômica Aplicada,

RATTS, A. Eu sou atlântica: sobre a trajetória de vida de Beatriz Nascimento. São Paulo, Instituto Kuanza, 2007.

RIBEIRO, D. O que é lugar de fala?. Belo Horizonte - MG. Letramento: Justificando, 2019.

ROSA, L. D. Eu, mulher, negra, jovem universitária: Discriminação racial no contexto universitário. Unipampa, 2017. Disponível em: 位. /riu/2719/1/TCC\%20Luiza\%20Dutra\%20 sidade Federal da Bahia, p. 128, 2018. 20 17.pdf> Acesso em: 10 de mai. 2019.

SANTOS FILHO, A. Racismo e Relações Raciais. In: CONSELHO REGIONAL DE PSICOLOGIA DA BAHIA. Psicologia e direitos humanos: compromisso ético-político e transformações sociais. Salvador: CRP-03. 2019, p. 23-25. Disponível em: $<$ https://www.crp03.org.br/wpcontent/uploads/2020/02/crp03_direitos_h umanos_livreto_digital-1.pdf>. Acesso em: 26 de jun. 2020.

SANTOS FILHO, A. Repercussões do racismo institucional na saúde mental de negros universitários. 2020. Trabalho de Conclusão de Curso (Graduação em Psicologia). Universidade do Estado da Bahia, Salvador, 2020 .

SANTOS, G. G.; SILVA, S. L. C. A evasão na educação superior entre debate social e objeto de pesquisa. In: SAMPAIO, S. M. R. (org.). Observatório da vida estudantil: primeiros estudos [online]. Salvador: EDUFBA, 2011.

SANTOS, N. Tornar-se negro: as vicissitudes do negro brasileiro em Ascensão social. RJ. Graal, 1983.

SILVA JR., H. Discriminação racial nas escolas: entre a lei e as práticas sociais. Brasília: UNESCO, 2002.

SILVA, A; PINHO, C. M. S. Epistemicídio, Racismo E Educação: Considerações Epistemológicas a partir de Boaventura de Sousa Santos. IN: Congresso de Pesquisa em Educação: Educação e resistência em tempos de crise política, 2018, Rondonópolis. Anais. Rondonópolis: UFMT, 2018.

SILVA, S. A. Travessias improváveis: Permanência de estudantes das camadas populares no curso de Medicina da Universidade Federal da Bahia. Dissertação (Mestrado em Psicologia) - Instituto de Psicologia, Programa de TOKARNIA, M. Negros representam 28,9\% dos alunos da pós-graduação. Agência Brasil. Brasília, 13 de maio de 2015. Disponível em: $<$ http://agenciabrasil.ebc.com.br/educa cao/noticia/2015-05/negrosrepresentam-289-dos-alunos-da-posgraduacao>. Acesso em: 20 de jun. 2020 . 